\title{
Clinical Characteristics of the 2013 Haiyan Typhoon Victims Presenting to the Belgian First Aid and Support Team
}

Gerlant van Berlaer, PhD; Frank de Jong, RN; Timothy Das, RN; Carlos Primero Gundran, MD; Matthiijs Samyn, RN; Geert Gijs, RN; Ronald Buyl, PhD; Michel Debacker, MD; Ives Hubloue, PhD

\section{ABSTRACT}

Objective: In 2013, the Philippines was struck by typhoon Haiyan, which damaged local hospitals and disrupted health care. The Belgian First Aid and Support Team erected a field hospital and water purification unit in Palo. This study aims to describe the diagnoses encountered and treatment provided.

Methods: In this cross-sectional study, medical records of 1267 field hospital patients were reviewed for gender, age, complaints, diagnoses, and management and referral information.

Results: Almost $28 \%$ of the patients suffered from injury, but most presented with nonsurgical diseases $(64 \%)$, particularly of respiratory (31\%), dermatological (11\%), and digestive (8\%) origin. Only 53\% presented with disaster-related pathology, and $59 \%$ showed signs of infection. Patients needed wound care $(47 \%)$, pain relief (33\%), or antibiotics (29\%); $9 \%$ needed procedures, $8 \%$ needed fluid therapy, and $5 \%$ needed psychological support. Children under 5 years of age were more at risk for infections (OR, 18.8; $\mathrm{Cl}, 10.6-33.3)$ and injuries (OR, 10.3; $\mathrm{Cl}, 6.3-16.8)$. Males were more prone to injuries than females (OR, 2.1; $\mathrm{Cl}, 1.6-2.6)$.

Conclusions: One week after the acute phase of a typhoon, respiratory, dermatological, and digestive problems emerge to the prejudice of trauma. Only 53\% of patients presented with disaster-related conditions. Young children are more at risk for injury and infectious diseases. These trends should be anticipated when composing Emergency Medical Teams and medical resources to be sent to disaster sites. (Disaster Med Public Health Preparedness. 2019;13:265-278)

Key Words: Philippines, typhoon, disaster, field hospital, emergency medical team

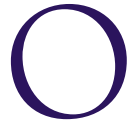
n November 8, 2013, typhoon Haiyan (locally named Yolanda) made landfall on the Philippine islands. On its trail through the country, it affected 14.1 out of 92.3 million inhabitants, with 36600 casualties (6183 dead, 28626 injured, and 1785 missing) and 4.1 million displaced persons (nearly all in the Western and Eastern Visayas regions), of whom only 101527 found shelter in one of the 381 governmental evacuation centers. The majority of displaced persons relocated in self-created temporary shelters. ${ }^{1-3}$

Among the worst-hit areas was the east coast of Leyte Island in the Eastern Visayas region. This area has 4 million inhabitants. ${ }^{1}$ In addition to the extreme winds, a tidal wave also made land, leaving half a million houses uninhabitable. In Leyte alone, 5290 people were killed, 15609 were injured, 1671 were missing, and over 1 million (55\% of the population) were displaced-desperate for food, safe drinking water, basic shelter, and sanitation. ${ }^{1}$

Many health care facilities, including hospitals, were damaged and either shut down or only partially functional. On top of that, most health care providers were affected themselves. On November 9, the Philippine government accepted the United Nations' offer of international assistance, resulting in an immediate global humanitarian response with 151 emergency medical teams (EMTs) providing medical services. ${ }^{4}$ The Belgian First Aid and Support Team (B-FAST), with trained medical and logistic professionals cooperating with diplomatic personnel, was assigned to the region southeast of Tacloban. They were the first international team with an operational field hospital in Palo, a city with about 57000 inhabitants on the east coast of the island of Leyte. ${ }^{4,5}$ The deployment in Palo was delayed by several days because of difficulties in reaching the area with large planes transporting 28 tons of material. Starting on day 8 after the event, the team provided acute care to 1267 patients, retrieving medical supplies primarily from preconfigured interagency emergency health kits (IEHK). ${ }^{6}$ At the same time, a Belgian water purification unit was installed near the river Buri, providing about 4000 liters of drinking water per hour. The team provided free health care to any patient presenting, considering the Philippines' health 
insurance system covers only basic and limited health care even in times without a disaster. More advanced treatment was available in the Australian and Médecins Sans Frontières field hospitals and in the Philippine Eastern Visayas Regional Medical Centre in Tacloban, a 30-minute drive from Palo. However, the latter services were less affordable and too expensive for most residents of the region. ${ }^{7}$

A prerequisite to adopting any evidence-based approach in humanitarian response is to assemble a solid body of evidence from results of relevant empirical studies. ${ }^{8}$ Collecting reliable data will always be difficult in emergency situations, as health care providers prioritize treating casualties over documenting, and control groups are usually not available. ${ }^{9}$ A literature search reveals that epidemiological studies and published reports on health problems of disaster patients vary widely in methodology and points of interest and are often expert opinions or undocumented statements. ${ }^{10}$ Most articles focus on selected issues, like injuries and communicable diseases, or elucidate immediate effects of disasters (estimated numbers of dead, injured, and displaced) and late consequences such as outbreaks, epidemics, and mental health problems. ${ }^{10,11} \mathrm{Few}$ reports of EMTs provide a comprehensive and complete overview of the encountered pathology of all the patients they treated. ${ }^{4,10,12,13}$

This study aims to document the demographics, complaints, comorbidities, diagnoses, diagnosis categories, and management of typhoon victims who sought medical assistance in a field hospital of an international EMT and to formulate recommendations for future relief operations.

The hypothesis is that medical problems besides disasterrelated trauma emerge quickly, and that this has implications for the appropriate composition of EMTs and supplies.

\section{METHODS}

\section{Study Design}

A retrospective, descriptive, cross-sectional sample analysis was performed on prospectively obtained medical records collected by B-FAST from November 16 to November 20, 2013. This time interval corresponds to the period that the Belgian field hospital was present in Palo.

\section{Setting}

B-FAST erected an enhanced level I medical-surgical field hospital with units for 24/7 triage, ambulatory emergency care, surgery, recovery, and psychosocial support, as well as a small short stay unit. The B-FAST volunteer team comprised 5 physicians ( 1 surgeon, 3 anesthesiologists trained in emergency medicine, and 1 pediatrician); 15 skilled nurses, of whom 1 was of Philippine origin; 1 pharmacist; 4 water and sanitation personnel; and 10 logisticians, interpreters, and communication and information specialists. B-FAST registered all volunteers and verified their diplomas and licenses to work as health care providers. The team was supported by members of the German International Search and Rescue Team (ISAR), and the 2 groups functioned jointly in the same field hospital.

Patients presented to the field hospital by their own means. Registration on admission and simple triage and rapid treatment (START) were performed by trained nurses and physicians. For all patients who received care in the field hospital and who provided oral informed consent, paper World Health Organization (WHO) health cards were completed, recording age, gender, vital parameters (body temperature, body weight, heart rate, and blood pressure), and 1 chief complaint and all secondary complaints as expressed by the patient (or the legal guardian in the case of young children). Each patient was subsequently interviewed and examined by physicians, with competent interpreters present during clinical encounters. The physician registered 1 primary diagnosis, all secondary diagnoses, comorbidities, and initiated treatment (drugs, materials, anesthesia, procedures, and referral). Diagnoses were based on complaints and physical examination, as B-FAST had limited access to diagnostic capability at the time. Patients were treated on the spot, if appropriate, or were provided with ambulatory treatment and explanations in their native language. Supplies, materials, drugs, and infusions were retrieved from preconfigured IEHKs. Patients requiring follow-up were asked to return to the field hospital, and those who needed hospitalization or advanced care were transferred to nearby national or international health care services, with referral letters in English. B-FAST reported daily to the Philippine Department of Health using the Surveillance in Post Extreme Emergencies and Disasters (SPEED) template. In accordance with to the B-FAST exit strategy, after 5 days the compound was handed over to a German nongovernmental organization for continuation of services until the end of January 2014. An impression of the work in the field hospital can be seen in a British Broadcasting Corporation World News video. ${ }^{14}$

\section{Participants: Cohort Subject Selection}

All patients presenting spontaneously to the field hospital were eligible for inclusion. Patients with missing chief complaint or single primary diagnosis were excluded. Patients younger than 18 years old were considered a child. ${ }^{15}$

\section{Variables}

A prospectively designed template based on the WHO Health Card was used to register data for all patients: age, gender, date of encounter, all physical and mental complaints, the chief complaint, and all pre-existing comorbidities. ${ }^{16,17}$ Diagnoses were based on complaints and physical examination; the B-FAST team had little access to laboratory or imaging diagnostic capability. One primary diagnosis per patient was recorded according to a list of 63 possible diagnoses, adapted from case descriptions in the WHO Communicable Disease Control in Emergencies field manual, the Sphere Project Handbook, and a template used in previous 
humanitarian operations. ${ }^{18-22}$ All secondary diagnoses were recorded separately. The diagnoses were subsequently categorized by trained physicians according to the International Classification of Diseases version 10 (ICD-10) classification, as described in Table $1 .{ }^{23}$ All patients with clinical signs of local or generalized infection were classified as a subgroup of "infectious diseases," as indicated with an asterisk in Table 1, and a subanalysis was performed regarding trauma versus nontrauma diagnoses. Finally, referral was recorded.

\section{Data Sources}

The study protocol was approved by the Ethical Committee of the Universitair Ziekenhuis Brussel, Belgium. All B-FAST data were processed after anonymization according to the Helsinki Declaration. ${ }^{24} \mathrm{~A}$ data sharing and research collaboration agreement was signed between B-FAST and the Research Group on Emergency and Disaster Medicine, Vrije Universiteit Brussel, Belgium.

\section{Bias}

Data were recorded by different health care providers working in shifts, and the anonymous records did not allow distinguishing patients possibly inserted twice, which could have introduced sampling bias. Diagnoses were subsequently categorized, which could have introduced categorization bias.

\section{Statistical Methods and Data Analysis}

Patients with missing or unreadable data were excluded. Descriptive statistics for discrete outcome variables were presented as frequencies (n) and proportions (\%), and descriptive statistics for quantitative variables (age, number of patients) were presented as measures of central tendency and dispersion: median, range, and interquartile range (IQR). The analyses were broken down for age categories $(<5$ and $\geq 5$ years old) and gender.

Pearson's chi-square analysis was performed to identify factors associated with the health problems by using "infectious disease," "injury," and "infected wounds" as outcome variables and by using age category ( $<5$ and $\geq 5$ years old) and gender as associated factors. Crude odds ratios were adjusted using multiple logistic regression analysis. Overall goodness of fit was evaluated using a likelihood ratio test and the Hosmer-Lemeshow test. Model quality was evaluated using Nagelkerke's R2.

Analyses were carried out by using International Business Machines Corporation, Statistical Package for Social Science $\left(\right.$ IBM $^{\circledR}$ SPSS $^{\circledR}$ v24.0). All tests were performed using an $\alpha$ level of 0.05 .

\section{RESULTS}

\section{Participants}

Seventeen forms were excluded because of missing data (unreadable or nonexistent notes regarding chief complaint or primary diagnosis). In all, 1267 patients were included and analyzed in this study.

\section{Descriptive Data}

Of 1267 included patients, 614 (48\%) were male and 636 $(50 \%)$ were female; the genders of $16(1.3 \%)$ were unknown. The median age was 26 years (range 0-89; IQR 42). Almost $8 \%(n=101)$ were older than 65 years, over $38 \%(n=490)$ were minors ( $<18$ years), and 261 patients $(21 \%)$ were $<5$ years old. Of 3 patients, the exact age was missing on the form.

\section{Outcome Data}

A total of 2164 patient's complaints (64 different types) were recorded: 596 patients (47\%) expressed a single complaint, 473 (37\%) expressed 2 complaints, 170 (13\%) expressed 3 complaints, and 28 (2\%) expressed 4 or more complaints. The most common primary complaints were cough $(\mathrm{n}=275 ; 22 \%)$, skin wounds $(\mathrm{n}=226 ; 18 \%)$, skin infection $(\mathrm{n}=98 ; 8 \%)$, fever $(\mathrm{n}=80 ; 6 \%)$, and accidental trauma $(\mathrm{n}=62 ; 5 \%)$ (Figure 1). Lack of chronic medication was noted in 10 patients $(1 \%)$, and more than $5 \%(n=66)$ of patients revisited for follow-up.

When the patients' complaints were categorized according to ICD-10, $52 \%$ of all patients expressed respiratory complaints $(n=655), 38 \%$ were injured $(n=476), 17 \%$ had skin problems $(n=218), 14 \%$ had digestive complaints $(n=181)$, $7 \%$ had musculoskeletal complaints $(n=90)$, and $5 \%$ had neurological complaints $(n=61)$. Sixteen percent $(n=208)$ complained of general infectious diseases, and 6\% $(n=82)$ presented for follow-up. All other categories represented less than $5 \%$ of all patients.

More than $9 \%$ of patients $(n=110)$ reported 1 or 2 comorbidities, most commonly diabetes $(n=23)$ or arterial hypertension $(n=14)$. Patients also reported asthma $(n=11)$, rheumatic diseases $(n=10)$, pregnancy $(n=8)$, epilepsy $(n=4)$, and neoplasms $(n=3)$.

Of all patients seen by B-FAST after the typhoon, 753 (59\%) had features of infectious diseases. This was far more pronounced in the $<5$ year old subgroup (247 out of 260 [95\%] in the $<5$ year old subgroup versus 506 out of 1007 [50\%] in the $\geq 5$ year old subgroup).

In children under 5 , most diagnoses were of respiratory $(n=146 ; 56 \%)$, digestive $(n=53 ; 20 \%)$, or dermatological $(\mathrm{n}=31 ; 12 \%)$ origin. Nine $(3 \%)$ suffered from injuries, almost all from acute wounds $(n=8)$.

\section{Main Results}

As represented in Figure 2 and Table 1, the most common primary diagnoses consisted of skin wounds and burns (23\%), upper respiratory tract infections (15\%), skin infections (9\%), 
TABLE 1

\section{Diagnostic Categories, Primary Diagnoses, and Case Descriptions}

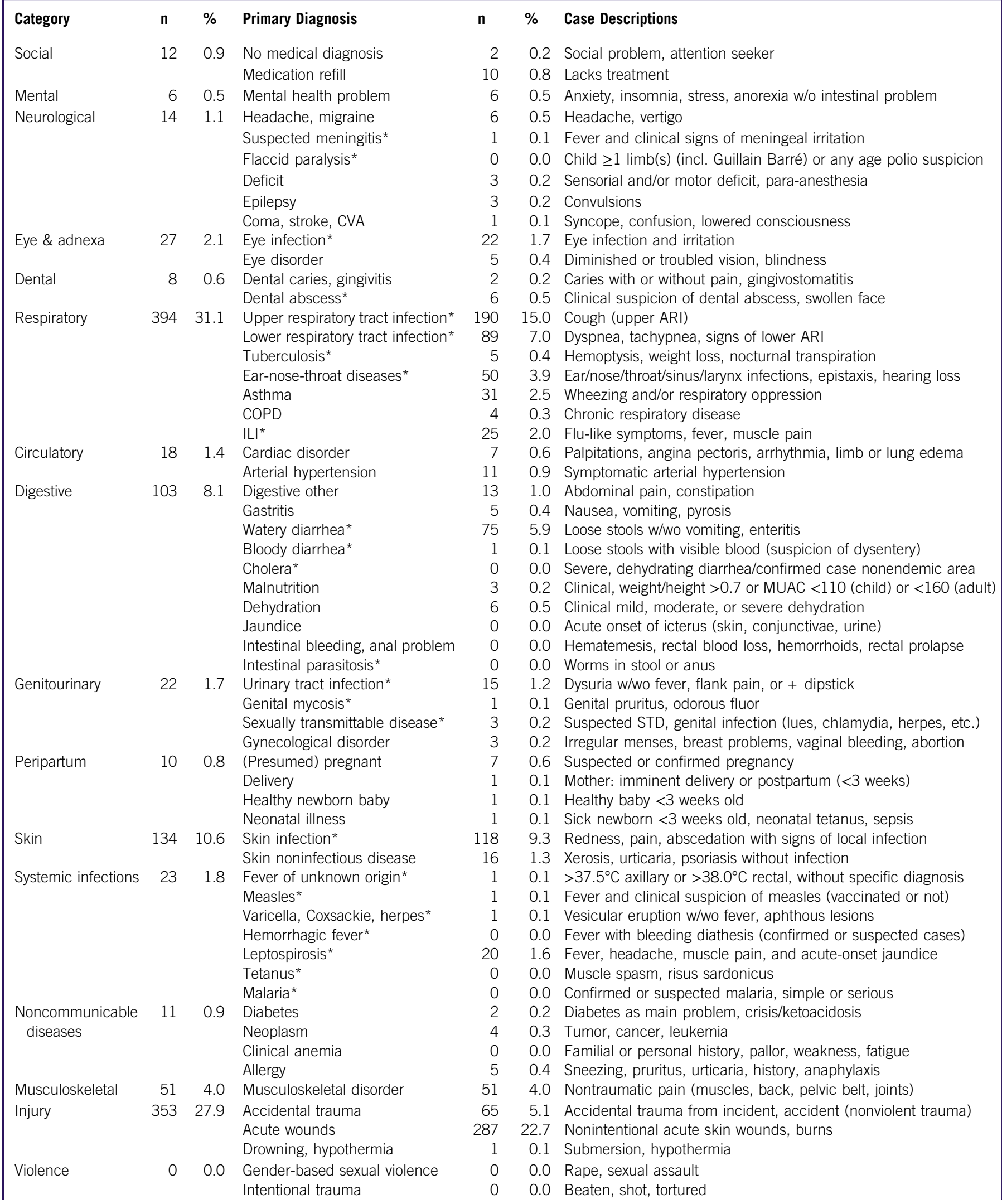


TABLE 1

\section{(Continued)}

\begin{tabular}{|c|c|c|c|c|c|c|}
\hline Category & $\mathbf{n}$ & $\%$ & Primary Diagnosis & $\mathbf{n}$ & $\%$ & Case Descriptions \\
\hline \multirow[t]{3}{*}{ Other } & 14 & 1.1 & Nontrauma surgical case & 8 & 0.6 & Hernia, swollen testicles, cysts, gallstones, nephrolithiasis, etc. \\
\hline & & & Nontrauma medical emergency & 2 & 0.2 & Resuscitation, thyroid storm, Addison crisis, etc. \\
\hline & & & Other & 4 & 0.3 & All not classified elsewhere \\
\hline \multirow[t]{2}{*}{ Fatality } & 1 & 0.1 & Death & 1 & 0.1 & Deceased patients \\
\hline & & & Total & 1267 & 100 & \\
\hline \multirow{2}{*}{ Subanalysis } & & & Injuries & 446 & 35.2 & All cases with injuries (primary and secondary diagnoses) \\
\hline & & & Infected wounds & 51 & 4.0 & All cases with infected event-related wounds \\
\hline
\end{tabular}

Abbreviations: ARI, acute respiratory infection; CBRN, chemical-burns-radiological-nuclear incidents; COPD, chronic obstructive pulmonary disease; CVA, cerebrovascular accident; ILI, influenza-like illness; MUAC: middle upper arm circumference, incl., including; STD, sexually transmittable disease; w/o, without; w/wo, with or without; + , positive; *, cases with features of infection.

\section{FIGURE 1}

\section{Twenty Most Common Primary (Red) and Secondary (Blue) Complaints Expressed by the Patients (\% of All Patients).}

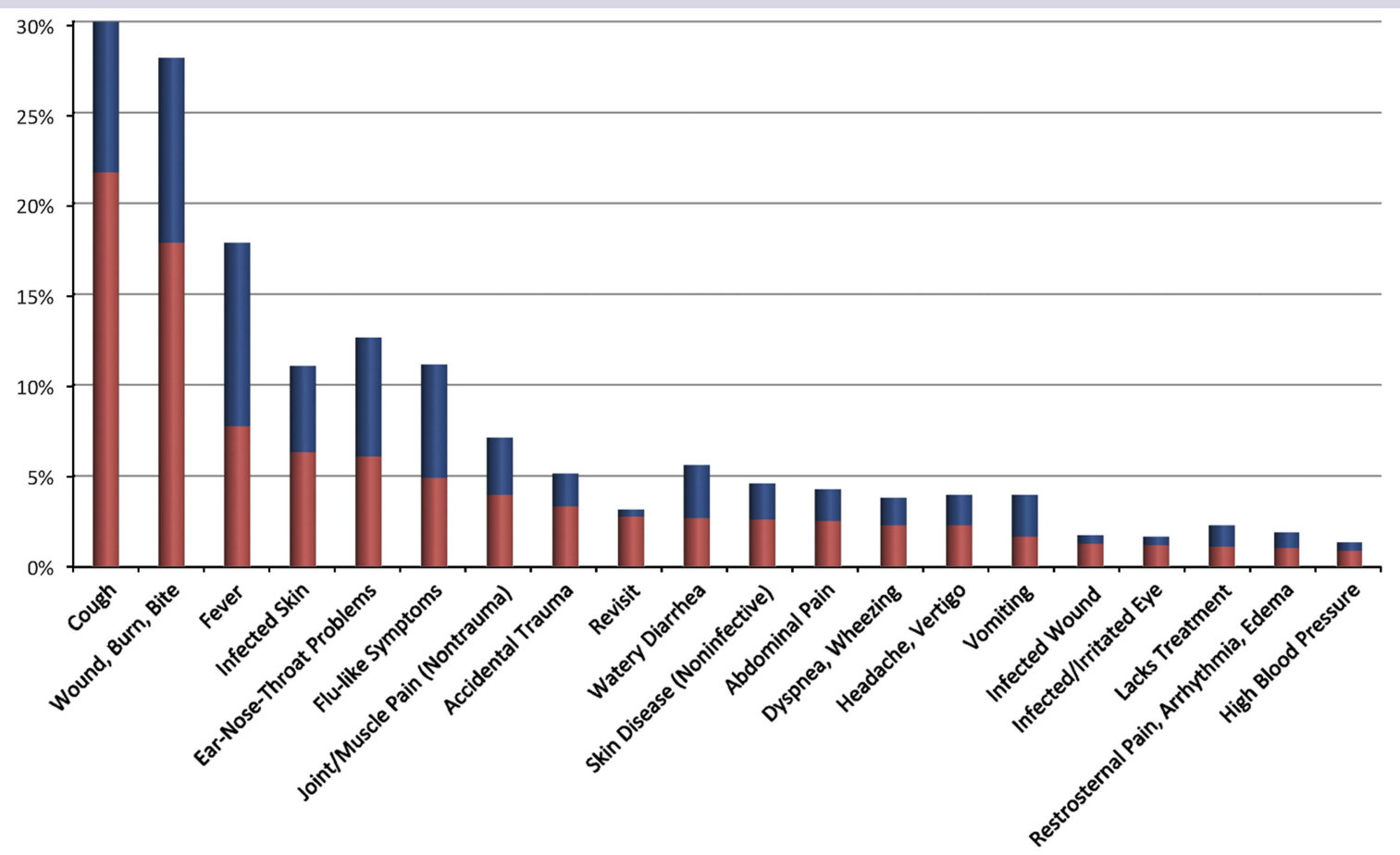

pneumonia (7\%), gastroenteritis (6\%), and accidental trauma (5\%). Mental disorders were chief diagnosis in $0.5 \%$. One patient died, and 1 healthy baby was born after a complicated assisted delivery.

Table 1 and Figure 3 indicate the distribution of diagnostic categories. The most frequent were respiratory disorders $(31 \%)$, injury (28\%), skin (11\%), and digestive (8\%). Fiftyone $(4 \%)$ patients presented with infected wounds. In 12 cases $(1 \%)$ there was no actual medical or mental diagnosis, but the patient was in search of routine daily medication or requested personal attention.

\section{Management Analysis}

Supplies, materials, infusions, and drugs were mainly retrieved from preconfigured IEHKs. These do not contain oxygen or antidiabetics, as these supplies come in separate additional 
FIGURE 2

Twenty Most Common Primary (Red) and Secondary (Blue) Diagnoses Observed (\% of All Patients).

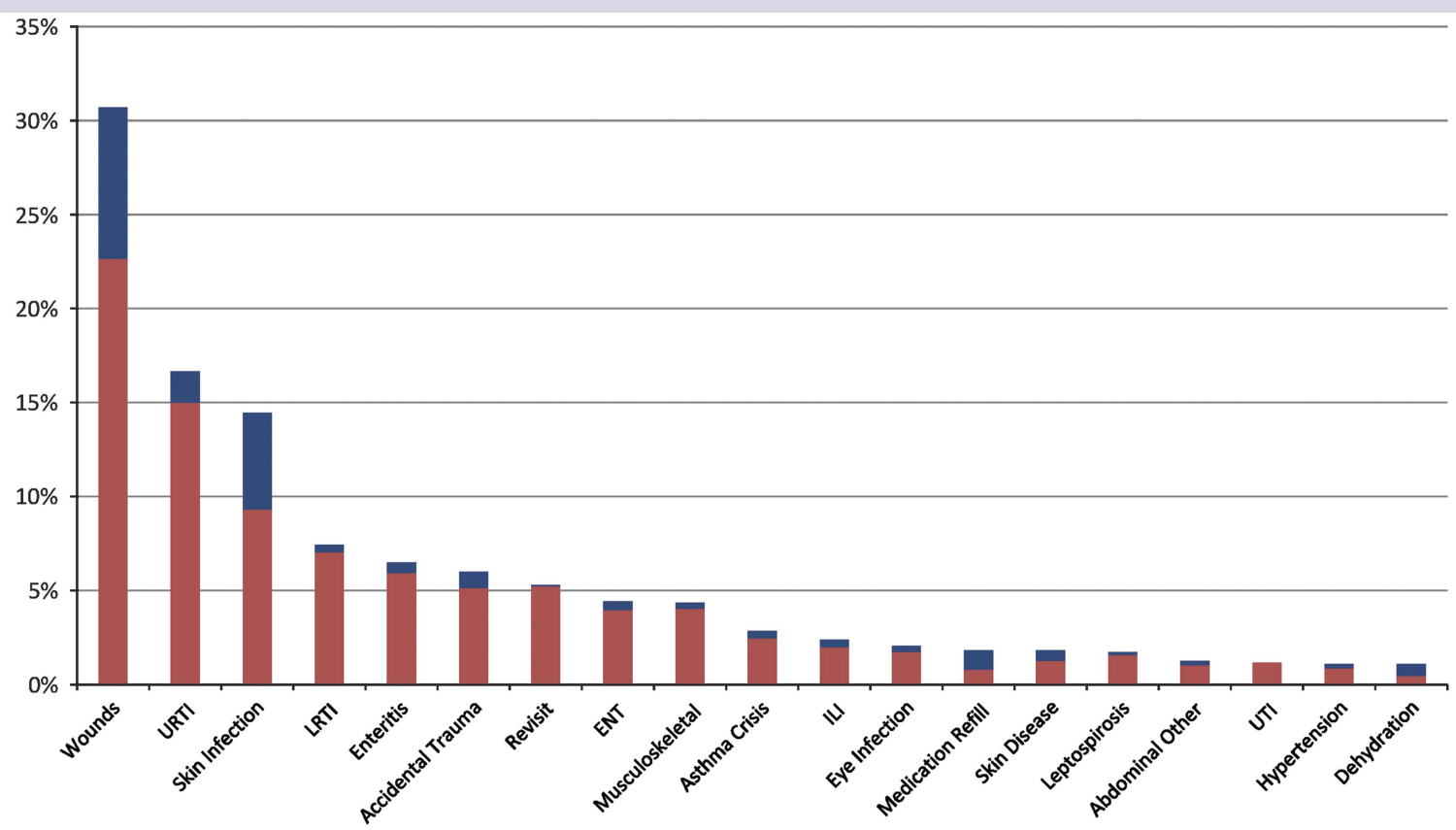

Abbreviations: ENT, ear-nose-throat infection; ILI, influenza-like illness; LRTI, lower respiratory tract infections; URTI, upper respiratory tract infection; UTI, urinary tract infection.

\section{FIGURE 3}

\section{Proportions of Diagnostic Categories (\% of Patients Affected).}

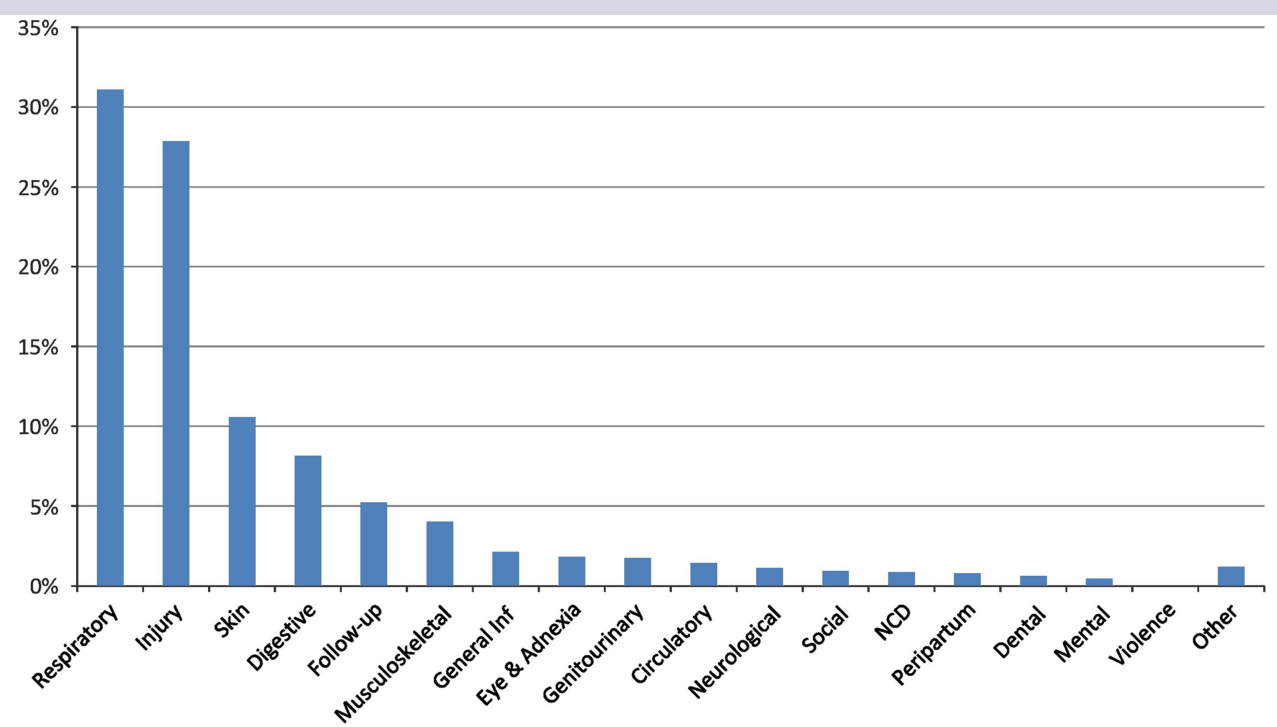

Abbreviations: Inf, infection; NCD, noncommunicable diseases.

kits or have to be added from other supplies. As demonstrated in Figure 4, the most-used treatment was wound care in general (rinsing, disinfection, local antibiotics and povidoneiodine, dressings, sutures or stitching, sulfadiazine), followed by pain relief (paracetamol, nonsteroidal antiinflammatory drugs, opioids in oral and parenteral forms, and anesthetic gels for wounds), the distribution of vitamins and minerals (from the IEHK: zinc, iron, vitamin C), and antibiotics (most 
FIGURE 4

\section{Categories of Management (\% of Patients)}

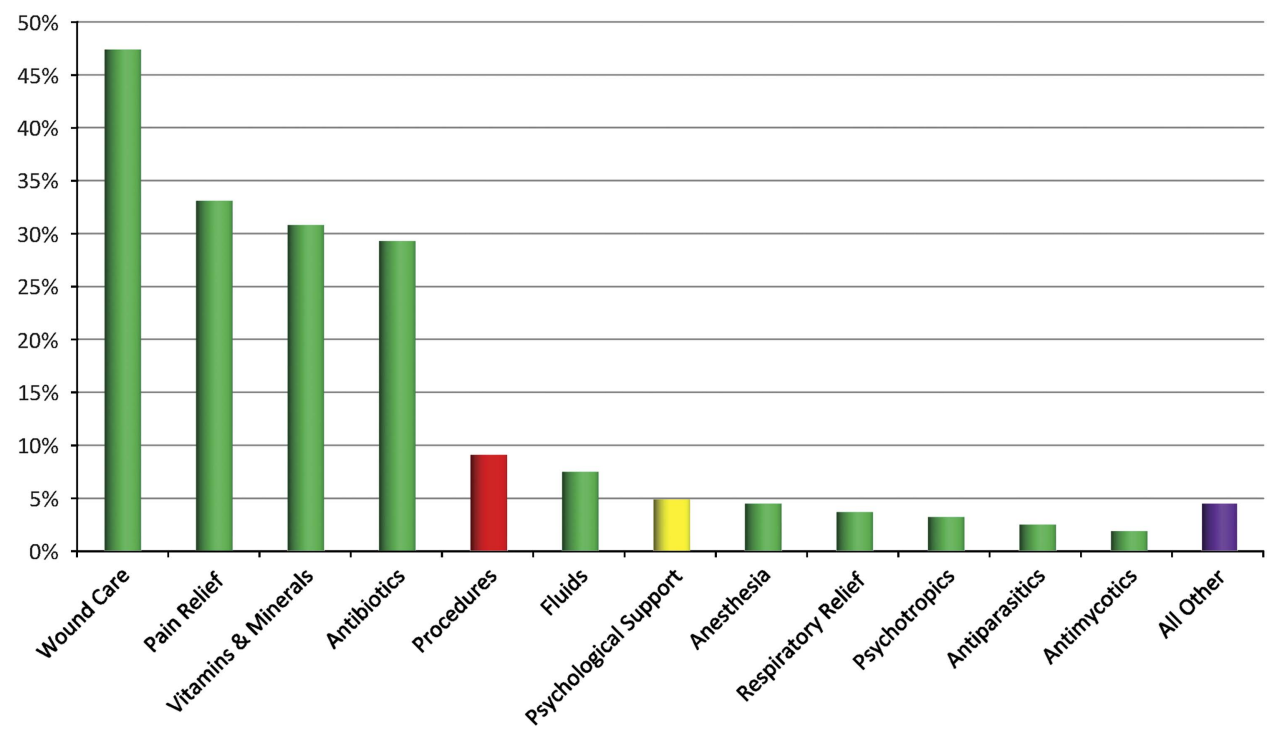

\section{TABLE 2}

\section{Distribution of Infectious Cases Over Age Groups}

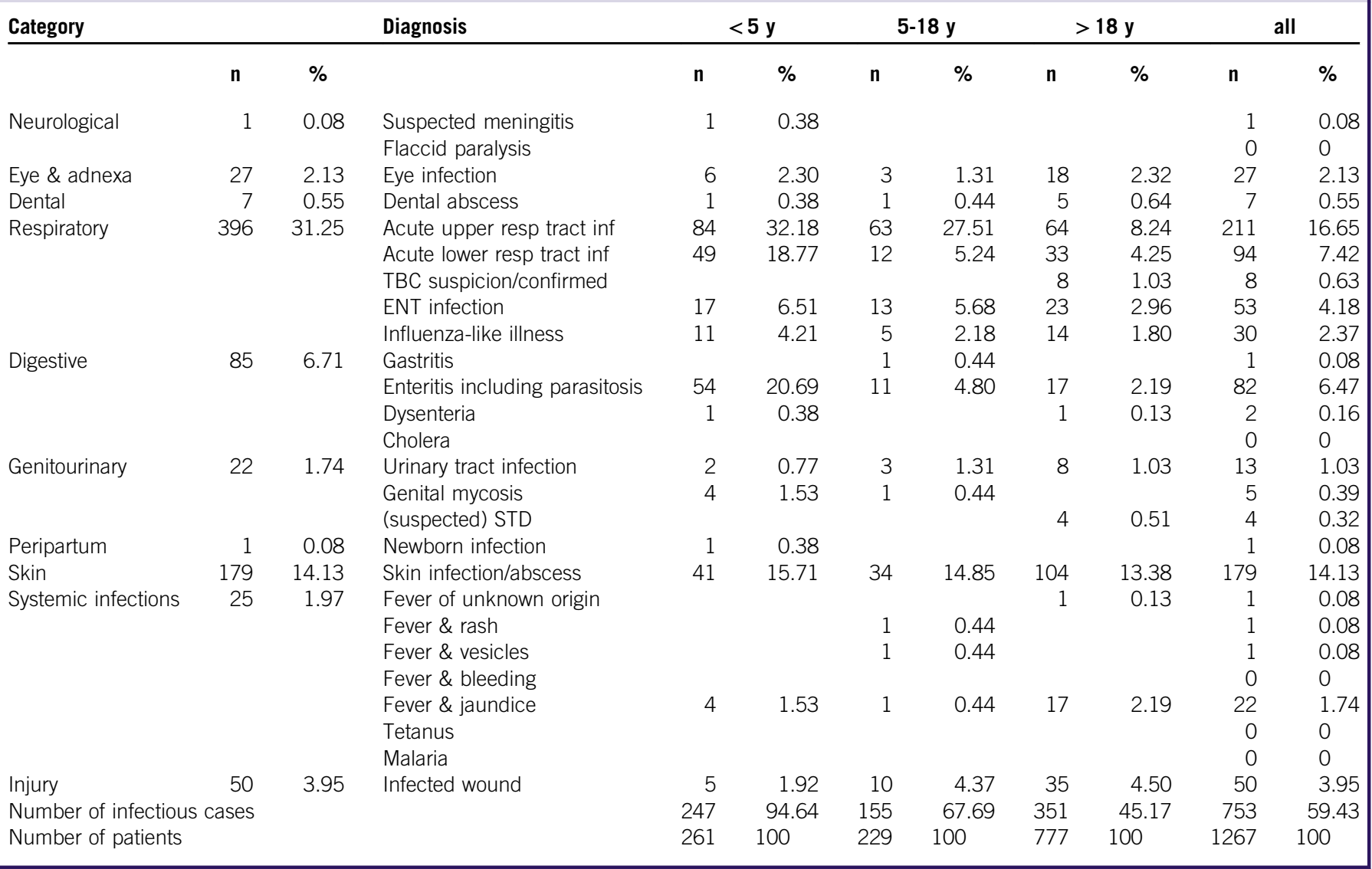

Abbreviations: ENT, ear-nose-throat; inf, infection; resp, respiratory; STD, sexually transmittable disease; TBC, tuberculosis; y, years old. 
patients received narrow-spectrum oral antibiotics, except for the surgical patients, who received intravenous broadspectrum antibiotics). Antiparasitic drugs and antimycotics were used for $3 \%$ and $2 \%$ of patients, respectively. Respiratory relief was mainly achieved by the use of bronchodilators. Procedures were performed on $9 \%$ of patients $(n=115)$, including 15 major and 30 minor surgical interventions. Forty-two patients had to be transferred to secondary care hospitals for complex surgery, transfusions, and intensive postoperative care. In the field hospital, anesthetics were only used in patients undergoing surgical procedures. Psychological support was delivered to $5 \%$ of patients $(n=62)$, and psychotropic drugs to $41(3 \%)$.

\section{Subgroup Analyses}

Children under $5 \quad(n=261)$ represented $21 \%$ of the population. The distribution of diagnostic categories indicates that $56 \%$ had respiratory diseases $(n=146), 20 \%$ had digestive disorders $(\mathrm{n}=53), 12 \%$ had skin disorders $(n=31), 3.5 \%$ suffered from injuries $(n=9)$, and 1 healthy baby was born in the field hospital after a complicated assisted delivery.

Features of infection were found in 753 patients (59\%), with an even higher frequency (247 out of 260 [95\%]) in children under 5 years of age. Of all 753 infectious cases, 402 were pediatric patients: 247 among the $<5$-year-old group and 155 in the 5- to 18-year-old group (Table 2).

Among children under five, 95\% had features of infectious disease, involving the respiratory system (62\% of patients), the intestinal system ( $21 \%$ of patients), the skin $(16 \%$ of patients), the eye ( $2 \%$ of patients), the genitourinary system ( $2 \%$ of patients), and infected wounds ( $2 \%$ of patients).

Of the older children, $68 \%$ showed features of infections, involving the respiratory system ( $41 \%$ of patients), the skin ( $15 \%$ of patients), the intestinal system ( $5 \%$ of patients), wound infections ( $4 \%$ of patients), the eye ( $1 \%$ of patients), and the urinary tract $(2 \%)$.

Among adults, 45\% had features of infections, involving the respiratory system (18\% of patients), the intestinal system ( $18 \%$ of patients), the skin ( $13 \%$ of patients), wound infections ( $5 \%$ of patients), and the genitourinary system ( $2 \%$ of patients).

Patients were asked to revisit to the field hospital for followup in $5 \%$ cases $(n=66)$. Overall, 54 patients $(4 \%)$ were referred for more advanced surgical or medical care, laboratory tests, and imaging diagnostics.

Analysis of the reasons for the encounters revealed that 671 patients $(53 \%)$ presented with injuries or diseases directly related to the typhoon; all others presented with health problems that could not be directly linked to the disaster.
Of the 353 patients with injuries, $87(25 \%$, or $7 \%$ of the total patient population) needed a surgical intervention, with need for intravenous anesthesia and fluid supplementation. The B-FAST team performed 30 minor and 15 major surgical procedures in the field hospital, while 42 of the surgical patients had to be referred to higher level (field) hospitals for advanced surgery and postoperative or intensive care.

Pearson's chi-square analysis identified age as a factor associated with infectious diseases and injury and gender as a factor associated with injury, as shown in Table 3 . We did not detect any other significant associated factors.

Crude odds ratios for the identified associated factors (gender and age) were adjusted using multiple logistic regression analysis (as indicated in Table 4), which revealed that children younger than 5 have a significantly higher risk for infectious diseases, and that male patients and children older than 5 have a higher risk for injury.

\section{DISCUSSION}

\section{Key Results}

When international EMTs are deployed to a disaster area to offer humanitarian relief to the affected population, they are often only prepared and designed to deliver medical assistance to patients suffering from major trauma or acute medical emergencies like drowning and burns. In our study population, it is striking that 1 week after the onset of the disaster, about half of the victims were seeking medical assistance for non-disaster related, nonsurgical issues, and only $7 \%$ needed surgical interventions. The most common diagnoses (wounds, upper respiratory tract infections, skin infections, pneumonia, gastroenteritis, accidental trauma) and the distribution of diagnosis categories reflected the typical morbidity profile of the country. ${ }^{25}$

There are several reasons for these findings. First, there are practical and political barriers that make it difficult for international teams to reach the affected area, which leads to delay in deployment. ${ }^{4}$ In this case, B-FAST could only start medical aid the second week after the onset of the event, when most major trauma cases had either resulted in death or been treated in nonaffected health care facilities. ${ }^{4,26,27}$ The EMT Initiative of the Global Health Cluster established in 2013 provides 2 solutions to avoid these delays: EMTs need to register in advance, which avoids a massive influx of numerous competing teams leading to overcrowding and coordination problems, and an EMT Coordination Cell-staffed with trained local and international coordinators-will facilitate direction and allocation of the (registered) EMTs to specific areas, so scarce transport services will not be dispersed. Second, typhoons do not usually cause large numbers of major trauma cases, when compared with other types of disasters. ${ }^{11}$ Third, in a population with limited basic health care services covered by 


\begin{tabular}{|c|c|c|c|c|c|}
\hline & Associated Factors & & & Significant & $P$ Value \\
\hline \multirow[t]{3}{*}{ Infectious } & Gender & Female & Male & & .915 \\
\hline & & 381 (59.9\%) & 366 (59.6\%) & & \\
\hline & Age & $\begin{array}{c}<5 \text { years } \\
247(95.0 \%)\end{array}$ & $\begin{array}{c}\geq 5 \text { years } \\
505(50.3 \%)\end{array}$ & + & $<.0001$ \\
\hline \multirow[t]{2}{*}{ Injured } & Gender & $\begin{array}{c}\text { Female } \\
183(28.8 \%)\end{array}$ & $\begin{array}{c}\text { Male } \\
255(41.5 \%)\end{array}$ & + & $<.0001$ \\
\hline & Age & $\begin{array}{c}<5 \text { years } \\
19(7.3 \%)\end{array}$ & $\begin{array}{c}\geq 5 \text { years } \\
426(42.4 \%)\end{array}$ & + & $<.0001$ \\
\hline \multirow[t]{2}{*}{ Infected wounds } & Gender & $\begin{array}{c}\text { Female } \\
26(4.1 \%)\end{array}$ & $\begin{array}{c}\text { Male } \\
24(3.9 \%)\end{array}$ & & .872 \\
\hline & Age & $\begin{array}{l}<5 \text { years } \\
5(1.9 \%)\end{array}$ & $\begin{array}{c}\geq 5 \text { years } \\
46(4.6 \%)\end{array}$ & & .052 \\
\hline
\end{tabular}

\section{TABLE 4}

Associated Factors for Infectious Diseases and Injury From a Multiple Logistic Regression Analysis

\begin{tabular}{|c|c|c|c|c|c|}
\hline & & \multirow[b]{2}{*}{$\mathbf{O R}$} & \multicolumn{2}{|c|}{$95 \% \mathrm{Cl}$ of $\mathrm{OR}$} & \multirow[b]{2}{*}{$P$ Value } \\
\hline & & & Lower & Upper & \\
\hline \multicolumn{6}{|l|}{ Infection $^{a}$} \\
\hline Gender (reference: female) & male & 1.2 & 0.9 & 1.5 & .258 \\
\hline $\begin{array}{l}\text { Age (reference: } \geq 5 \text { years old) } \\
\text { Injury }^{\mathbf{b}}\end{array}$ & $<5$ years old & 18.8 & 10.6 & 33.3 & $<.0001$ \\
\hline Gender (reference: female) & male & 2.1 & 1.6 & 2.6 & $<.0001$ \\
\hline Age (reference: $\geq 5$ years old) & $<5$ years old & 10.3 & 6.3 & 16.8 & $<.0001$ \\
\hline
\end{tabular}

Abbreviations: $\mathrm{Cl}$, confidence interval; OR, odds ratio.

'Likelihood ratio test $(\chi 2), P<.001$; Hosmer-Lemeshow test, $P=.388$; Nagelkerke's R2, 0.209.

bLikelihood ratio test $(\chi 2), P<.001$; Hosmer-Lemeshow test, $P=.713$; Nagelkerke's R2, 0.173 .

solidarity-based systems, people postpone seeking care for medical problems that are more chronical or less urgent or that they believe will require less affordable advanced care. Western medical teams deploying and providing free medical assistance may attract patients seeking advice and treatment for longer-lasting problems. ${ }^{7} \mathrm{~A}$ last reason could be related to the shift of all major hospitals into trauma centers and the deployment of more sophisticated field hospitals, which diverts nontrauma patients to lower level field hospitals like the B-FAST facility. ${ }^{20}$

Injuries were present in almost $28 \%$ of the patients' cases, a higher proportion than reported by other EMTs, as illustrated in Table 5. However, and consistent with other reports, the majority concerned acute and infected skin wounds needing debridement, revision, or surgical follow-up. ${ }^{28}$

More than half (59\%) of all patients, and almost all (95\%) of the children younger than 5 , showed features of infection. Destroyed shelter and lack of sanitation, water, and food, together with encampment in austere conditions, were most likely the primary contributors to this high proportion. ${ }^{11,29}$ Infections of untreated or undertreated typhoon-related wounds 1 to 2 weeks after the onset of the event contributed as well. ${ }^{28}$

The overwhelming presence of (mostly upper) acute respiratory infections is consistent with existing reports from other teams and other disasters, as visualized in Table 5. Because of huddling in temporary improvised shelters, respiratory infections may spread rapidly. ${ }^{29-31}$ Exposure to increased air pollutants, mold, and damp environments following hurricanes are additional contributing factors. ${ }^{12,31}$ This emergence of respiratory infections carries a possible burden, as it is a major cause of morbidity and mortality among displaced people, particularly among children. ${ }^{29,31-33}$ There were 5 patients with suspected tuberculosis, which is probably an underestimation as the Philippines had a high tuberculosis prevalence even before Haiyan. ${ }^{12,34}$

The improper sanitary conditions, disruption of the health system and interrupted surveillance probably resulted in a similar spread of skin, intestinal, genitourinary, and eye infections among the displaced population..$^{29,30,33}$ Although a community-based gastroenteritis outbreak was identified in Leyte as of the second week after the event, our sample did 


\section{TABLE 5}

\section{Comparison of Proportional Ranges Identified in Studies on Philippine Disaster Victims (\%).}

\begin{tabular}{|c|c|c|c|c|c|c|c|c|c|c|c|c|c|c|c|c|}
\hline Study & Situation & Respiratory & $\begin{array}{l}\text { Eye \& } \\
\text { Adnexa }\end{array}$ & Neurological & Dental & Digestive & Genitourinary & Peripartum & Skin & Mental & Injury & Musculoskeletal & Circulatory & $\begin{array}{l}\text { Infectious } \\
\text { Cases }\end{array}$ & NCD & Number \\
\hline This study & $\begin{array}{l}\text { Belgian FH } \\
\text { Palo }\end{array}$ & 31.1 & 2.1 & 1.1 & 0.6 & 8.1 & 1.7 & 0.8 & 10.6 & 0.5 & 27.9 & 4.0 & 1.4 & 59.4 & 0.9 & 1267 \\
\hline $\begin{array}{l}\text { Ranges in } \\
\text { literature }\end{array}$ & Haiyan & $23-62$ & $0-1$ & $0-5$ & $0-1$ & $4-40$ & $1-7$ & $0-2$ & $2-9$ & $0-1$ & $3-16$ & $1-13$ & $1-8$ & $5-80$ & $2-10$ & \\
\hline $\begin{array}{l}\text { Salazar } \\
{\text { et } a l^{5}}^{5}\end{array}$ & $\begin{array}{r}\text { Typhoon } \\
\text { SPEED }\end{array}$ & 62.0 & 0.5 & 0.2 & & 4.6 & & & 8.5 & & 10.3 & & 7.6 & & 8.2 & $>10000$ \\
\hline $\begin{array}{l}\text { Salazar } \\
\text { et }\left.^{26}\right|^{26}\end{array}$ & Haiyan SPEED & & & & & & & & & & 10.3 & & & 79.9 & 9.7 & 1614 \\
\hline $\begin{array}{l}\text { Chang } \\
{\text { et } \mathrm{al}^{12}}^{2}\end{array}$ & $\begin{array}{l}\text { CRC FH Ormoc } \\
\text { adult }\end{array}$ & 22.8 & & 4.0 & & 25.5 & 7.0 & 0.4 & 4.8 & 0.3 & 15.6 & 0.8 & 6.9 & 5.3 & 1.6 & 405 \\
\hline $\begin{array}{l}\text { Chang } \\
\text { et al }^{12}\end{array}$ & $\begin{array}{l}\text { CRC FH Ormoc } \\
\text { ped }\end{array}$ & 32.4 & 0.0 & 1.7 & & 39.9 & 4.6 & 0.2 & 2.6 & & 3.2 & 0.6 & 0.9 & 8.7 & 2.6 & 359 \\
\hline $\begin{array}{c}\text { Albukrek } \\
\text { et al }^{43}\end{array}$ & $\begin{array}{l}\text { Israel FH Cebu } \\
\text { ped }\end{array}$ & 45.8 & & 0.4 & & 4.1 & 0.8 & 1.9 & 8.7 & & 10.6 & & & & & 744 \\
\hline $\begin{array}{l}\text { Savage } \\
\text { et al }\end{array}$ & $\begin{array}{l}\text { CMAT OAT } \\
\text { Roxas }\end{array}$ & 46.5 & & 5.1 & 0.6 & 10.6 & 1.6 & 0.7 & 8.0 & 0.7 & 3.9 & 13.0 & 3.7 & & 3.0 & 6596 \\
\hline $\begin{array}{l}\text { Salazar } \\
\text { et al }\end{array}$ & $\begin{array}{l}\text { Disasters } \\
\text { Philippines }\end{array}$ & 32.9 & & & & 2.2 & & & 4.1 & & 5.2 & & & & 4.6 & 2747 \\
\hline $\begin{array}{l}\text { Salazar } \\
\text { et al }\end{array}$ & $\begin{array}{l}\text { Flood } \\
\text { Philippines* }\end{array}$ & & & & & & & & & & 8.1 & & & 88.7 & 3.3 & 551 \\
\hline $\begin{array}{l}\text { Salazar } \\
\text { et al }\end{array}$ & $\begin{array}{l}\text { Earthquake } \\
\text { Philippines* }\end{array}$ & & & & & & & & & & 9.2 & & & 77.8 & 9.2 & 582 \\
\hline $\begin{array}{l}\text { WHO } \\
\mathrm{GBD}^{44}\end{array}$ & $\begin{array}{l}\text { YLD Asia } \\
\text { Pacific* }\end{array}$ & 5.7 & & 15.7 & 1.3 & 7.4 & 1.0 & 7.9 & 0.5 & 15.7 & 10.9 & 5.5 & 4.2 & 19.0 & 2.1 & \\
\hline Kim et $\mathrm{al}^{45}$ & $\begin{array}{l}\text { FH Typhoon } \\
\text { Myanmar* }\end{array}$ & 17.2 & 5.9 & 4.7 & 1.5 & 14.6 & 2.7 & 1.4 & 7.4 & 9.0 & 4.8 & 16.7 & 3.9 & & 3.6 & 2641 \\
\hline $\begin{array}{l}\text { Bellos } \\
\text { et }\left.^{3}\right|^{32}\end{array}$ & $\begin{array}{l}\text { Review ARI in } \\
\text { crises* }\end{array}$ & $3-55$ & & & & & & & & & & & & & & 36 studies \\
\hline North et al ${ }^{41}$ & $\begin{array}{l}\text { Review mental } \\
\text { health*}\end{array}$ & & & & & & & & & $11-38$ & & & & & & 222 studies \\
\hline
\end{tabular}

Abbreviations: ARI, acute respiratory infections; CMAT, Canadian Medical Assistance Teams; CRC, Canadian Red Cross; FH, field hospital; GBD, global burden of disease; NCD, noncommunicable diseases; OAT, out-of-hospital team; ped, pediatric; SPEED, Surveillance in Post Extreme Emergencies and Disasters; WHO, World Health Organization; YLD, years lost to disability; ${ }^{*}$, studies not related the Haiyan crisis. 
not include an unusual high number of cases (6\%), which contrasts with reports from the Canadian Red Cross in Ormoc $(25.5 \%$ in adults to $39.9 \%$ in children) and the Canadian EMT in Roxas (10.6\%). ${ }^{12,35,36}$ Although cholera is endemic, there were no cases reported. This may be explained by the resilience of the Philippine community in terms of rapid installation of water purification units by EMTs like B-FAST, swift restoration of water and sanitation infrastructure, and the establishment of a surveillance system for early detection and treatment of cases of diarrhea by the Philippine authorities in accordance with the WHO. There were no reports of cholera outbreaks after typhoon Haiyan. ${ }^{37}$ Twenty-two patients ( 4 of the $<5$-year-old children, 1 older child, and 17 adults) with fever and jaundice were suspected of leptospirosis-also endemic in the Philippines, and a potential outbreak agent after floods-but there was no confirmation of these diagnoses. ${ }^{38}$ There were no suspected cases of other hemorrhagic fever syndromes, although dengue is endemic as well. An increase of dengue cases was not seen before January 2014. ${ }^{12,39}$ Eight adults were suspected of tuberculosis, and 4 of sexually transmittable diseases. There were no suspected cases of polio, malaria, or tetanus. Longterm conditions (including vector- and blood-borne infections such as HIV/AIDS, hepatitis B, and Helicobacter pylori) may have underpresented or been underdiagnosed, as health care providers focused more on identifying acute conditions and did not have access to the appropriate tests for these more chronic infections.

In children under 5 , respiratory, digestive, and skin infections emerged even more to the prejudice of trauma-related injuries, consistent with other reports. ${ }^{29,36}$ That only $4 \%$ of young children presented with injuries may be a consequence of the low survival rate of seriously injured children. ${ }^{27,40}$ Regardless of the age group, all patients suffered mainly from respiratory infections $(62 \%$ of the $<5$-year-old children, $41 \%$ of older children, and $18 \%$ of adults), intestinal infections $(21 \%, 5 \%$, and $18 \%$, respectively) and skin infections $(16 \%$, $15 \%$, and $13 \%$, respectively), as shown in Table 2 . One infant was suspected of having meningitis, and 1 newborn of neonatal sepsis.

The proportion of mental disorders was surprisingly low $(0.5 \%)$ in contrast to other studies reporting incidences of mental disorders in up to one-third of postdisaster victims. ${ }^{41}$ B-FAST provided interpreters, but it is still possible that language barriers, limited time per consultation (due to the high number of patients presenting), and the notion that EMTs like B-FAST focus primarily on physical emergencies induced a possible underreporting of mental problems within this population. When analyzing the provided treatment, B-FAST recorded delivery of psychological support to 62 patients $(5 \%)$ and administration of psychotropic drugs to 41 patients (3\%), although only 6 patients mentioned mental problems (as primary or secondary complaint) upon presentation, and only 6 patients were diagnosed with mental problems as the primary diagnosis. This indicates that cultural differences between the Philippine patients and the Belgian and German caregivers may have played a role as well.

The proportion of noncommunicable chronic diseases (mainly diabetes, hypertension, and asthma) found in this study population, $6 \%$, was lower than the range seen in earlier reports, ${ }^{5,26}$ possibly attributable to the young median age of patients and the consideration that the peak presentation of these conditions-secondary to the disruption of the health care system - generally appears some weeks after the onset of the event. ${ }^{42}$ Some $2 \%$ of patients lacked routine medication, mostly for the chronic treatment of comorbidities like diabetes and hypertension, and were therefore at risk for deregulation of their clinical condition. Unfortunately, the widely used basic IEHK does not contain sufficient medication refills for these patients, so B-FAST provided, by own means, refills of medication and distribution of materials like beta-blockers, inhalers, and urine ketone strips and organized follow-up or referral.

As the IEHK were not developed for use in the aftermath of disasters, but rather for medical services in a nonacute refugee camp setting, the actual situation of international EMTs bridging time and space to fly inadequate materials to the affected area is not ideal. ${ }^{6}$ The drugs and materials arrive late in the affected area, and this limits the resilience of countries depending on external relief. Building local resilience may lie as well in stockpiling resources locally, although this may involve a considerable cost for drug expiration-date management, cooled or heated storage, personnel, and transport services. Advantages of the current situation are that EMTs - usually based in more wealthy countries - can reduce prices when ordering many kits at the same time, have more resources to keep the drugs up to date, and can bring drugs not included in the kits, all of which alleviate costs for the affected country.

Both the stockpiling of disaster-response equipment and drugs in strategic areas in disaster-prone regions, and the education of the population in order to understand regional risks and how to prepare for and respond to disasters are tools to achieve resilience of a country in case of a catastrophe. The WHO and the EMT Initiative have a central role in making disaster-prone countries meet those Sendai Framework targets. ${ }^{47}$

The pattern and distribution of morbidity and disease resulting from this study can be compared with ranges found in the literature in studies about storms and other disasters in the Philippines, as demonstrated in Table 5. All of the diagnosis categories in this study are within the ranges reported by other teams, except for higher rates of injuries and skin and eye infections and lower rates of noncommunicable diseases in our study population. Most studies used different reporting templates, covered different periods, or focused on specific diagnoses only, making comparison challenging and creating gaps in Table 5 . 


\section{Limitations and Strengths}

This study has several limitations. The EMT worked in a complex setting and environment. Although the team used forms based on WHO health cards and defined diagnoses as provided in standard manuals, the lack of uniform standards to register complaints, clinical features, and diagnoses makes comparison to other datasets challenging. ${ }^{9}$ A number of diagnoses remained tentative, since laboratory and imaging tests were unavailable to confirm the cases suspected of meningitis, pneumonia, tuberculosis, and leptospirosis. This study covered a limited number of patients from the province of Leyte that presented during 4 days only in the second week after the event, preventing extrapolation of results to other affected areas, to the whole aftermath period, and to all Philippine typhoon victims.

The strength of this study is the considerable number of welldocumented complaints and physicians' diagnoses. To the best of our knowledge there has not been a report on typhoon patients in such detail before.

\section{CONCLUSION}

\section{Interpretation}

Typhoon victims seeking medical assistance in the second week after the onset of the event suffered mostly from respiratory, skin, and digestive diseases, and 28\% needed care for injuries and infected wounds. More than half of the study population showed features of infection, with young children being most vulnerable.

The high proportion of communicable diseases in this internally displaced population suggests the value of early preventive measures, such as provision of shelter, reduction of overcrowding, prevention and treatment of malnutrition, and scaling up immunization coverage. ${ }^{29,32}$ Adequate sanitary facilities are imperative to prevent the spread of infections, and early resolute health care may prevent short- and longterm complications of infectious diseases. ${ }^{29,46}$

In the light of reaching the 2030 goals stated in the United Nations Sendai Framework for Disaster Risk Reduction, which target the enhancement of resilience of each disasterprone country, the results of studies like the current one can be integrated into and be used to support directed educational programs for the general population, including messages about personal hygiene, safety of water and food, and the importance of sanitation, as well as for regional and international medical personnel preparing to provide relief in the aftermath of disasters. ${ }^{47}$

In order for EMTs to meet the changing needs of victims in subsequent phases of the disaster response, they need to adapt the composition of the staff. ${ }^{26}$ EMT members are usually deployed in shifts of 1 to 2 weeks, in order to keep all team members fit to work in austere circumstances. The first to be sent to the affected area are type 2 and 3 EMTs with surgeons and wound experts, anesthesiologists, intensivists, and ancillary nurses, together with the necessary equipment and supplies. $^{26,48}$ Depending on the nature of the sudden onset disaster-high energy like in earthquakes, or lower impact like storms - the needs for more advanced types of EMTs as reference centers for major surgery may differ. In this case, given the lower number of injury cases and the lesser grade of injuries, EMT types 1 and 2 might have been sufficient. There is an early role in EMTs of all types for emergency physicians, pediatricians, gynecologists, midwives, pharmacists, and interpreters. ${ }^{12,43,49}$ EMTs should scale up within the second week after the event with internists (among whom infectiology specialists will be most useful), rehabilitation teams, and multilingual psychologists. ${ }^{13,50}$ The existing supply kits should be adapted to the specific medical needs of disaster victims in different phases of the relief effort by providing drugs and supplies for respiratory, digestive, ophthalmological, and noncommunicable diseases, as well as rehabilitation materials and pediatric formulas of essential medicines. ${ }^{6,11,26,49}$

\section{Generalizability}

The results of this study can help to better organize health care for disaster patients, particularly with respect to the composition of the EMTs and their medical resources. ${ }^{6}$ However, in order to meet the specific and changing needs of victims, more research is needed to compare and confirm the important share of medical problems in direct victims and displaced populations during the aftermath of different types of disasters. $^{51}$

The development of a standardized template to prospectively collect and subsequently analyze and report health data might make a substantial contribution to provide the evidence base for the effectiveness and efficiency of the preparation, management, and mitigation of humanitarian emergencies. ${ }^{8-10,17}$

\begin{abstract}
About the Authors
Department of Emergency and Disaster Medicine, Universitair Ziekenhuis Brussel, Brussels, Belgium (Drs van Berlaer, Debacker, and Hubloue); Research Group on Emergency and Disaster Medicine, Vrije Universiteit Brussel, Brussels, Belgium (Drs van Berlaer, Debacker, Hubloue, and Mr de Jong); Belgian First Aid and Support Team, Brussels, Belgium (Dr van Berlaer, Mr de Jong, Mr Das, Mr Samyn, and $\mathrm{Mr}$ Gijs); Department of Emergency Medicine, Universitair Ziekenhuis Antwerpen, Antwerp, Belgium ( $\mathrm{Mr}$ Das and $\mathrm{Mr}$ Gijs); Crisis Management at Federal Public Health Service, Belgium (Mr Das); Subcommittee on Disaster Risk Management, University of the Philippines, Manila, Philippines (Dr Gundran); Department of Emergency Medicine, campus Middelheim, Ziekenhuis Netwerk Antwerpen, Antwerp, Belgium (Mr Samyn); and Department of Public Health, Biostatistics and Medical Informatics Research Group, Vrije Universiteit Brussel, Brussels, Belgium (Dr Buyl).
\end{abstract}

Gerlant van Berlaer and Frank de Jong contributed equally to this work.

Correspondence and reprint requests to Gerlant van Berlaer, Laarbeeklaan 101, BE-1090 Brussels, Belgium (e-mail: gerlant.vanberlaer@uzbrussel.be). 


\section{Individual Contributions of Each Author}

- Conception and design of the study: GvB, FdJ, TD, MS, RB

- Acquisition of data: TD, FdJ, MS, GG, CPG

- Analysis and interpretation of data: RB, GvB, FdJ

Drafting the article: GvB

Revising the manuscript: GvB, TD, GG, CPG, MDB, IH

Final approval of the version submitted: GvB, FdJ, TD, MS, GG, CPG, $\mathrm{RB}, \mathrm{MDB}, \mathrm{IH}$

GvB was responsible for the study setup and was main investigator and principal author of the article. As the guarantor of the paper, GvB accepts full responsibility for the work and the conduct of the study; he had access to the data, and controlled the decision to publish. FdJ, TD, MS, and GG designed the prospective patient files, were responsible for the correct collection of data, and wrote parts of the methods and data interpretation section. GG is the Medical Coordinator for the Belgian First Aid and Support Team, while TD was team leader in Palo. They contributed to the text regarding background, methods and discussion. CPG was the chief Disaster Management Officer in the Philippines during the response to the disaster and was responsible for accurate description of the event. RB is professor in biostatistics and medical informatics and was invaluable for the setup of the study, the processing of the data, and the interpretation of the results including appropriate statistics and graphics. MD and $\mathrm{IH}$ corrected the setup and finalization of the study, contributed with scientific remarks, helped find the appropriate references, and made many corrections to the final text.

\section{World Health Organization Standards for Registration of All Human Medical Research}

All authors have completed the Unified Competing Interest form at www. icmje.org/coi_disclosure.pdf (available on request from the corresponding author).

\section{Ethical Approval}

Approval of the Commission of Medical Ethics (O.G. 016) of the Universitair Ziekenhuis Brussel, Brussels, Belgium was obtained (B.U.N. 143201731864).

\section{Informed Consent and Patient Details}

The free and informed consent of the subjects and/or their legal guardians was obtained before their inclusion in this study. No details on individual patients are given in the manuscript; all patients were anonymized in the registry and database in accordance with the Helsinki Declaration.

\section{Data Sharing Statement}

A data sharing and research collaboration agreement was signed between the Belgian First Aid and Support Team and the Research Group on Emergency and Disaster Medicine, Vrije Universiteit Brussel, Belgium. The corresponding author, Gerlant van Berlaer, had full access to all the data in the study and had final responsibility for the decision to submit for publication.

\section{REFERENCES}

1 Assessment Capacities Project. Philippines Typhoon Yolanda: Secondary Data Review. https://www.humanitarianresponse.info/sites/www.humani tarianresponse.info/files/assessments/140111\%20SDR\%20Yolanda\%20Phi lippines\%20final.pdf. Published January 2014. Accessed May 10, 2017.

2 Internal Displacement Monitoring Centre, Norwegian Refugee Council. Philippines: Comprehensive Response to Wave of Displacement Crisis Needed. http://reliefweb.int/sites/reliefweb.int/files/resources/201312-apphilippines-overview-en.pdf. Published December 9, 2013. Accessed May 10, 2017.

3 United Nations Office for the Coordination of Humanitarian Affairs (OCHA). Philippines: Pre-disaster Indicators Dashboard. https://public.tableau.com/en-us/ s/gallery/pre-disaster-indicators-dashboard. Accessed May 10, 2017.

4 Brolin K, Hawajri O, von Schreeb J. Foreign medical teams in the Philippines after Typhoon Haiyan 2013 - Who were they, when did they arrive and what did they do? PLoS Curr. 2015:7. ecurrents. dis.0cadd59590724486bffe9a0340b3e718.

5 Salazar MA, Law R, Pesigan A, et al. Health consequences of Typhoon Haiyan in the Eastern Visayas region using a syndromic surveillance database. PLoS Curr. 2017 Feb 6:9. pii: ecurrents.dis.4a3d3b447 4847b2599aa5c5eefe3a621.

6 World Health Organization. The Interagency Emergency Health Kit 2011. World Health Organisation Technical Report Series 2011. http://www.who.int/ medicines/publications/emergencyhealthkit2011/en/. Accessed May 10, 2017.

7 Lin G, Marom T, Dagan D, et al. Ethical and surgical dilemmas in patients with neglected surgical diseases visiting a field hospital in a zone of recent disaster. World J Surg. 2017;41(2):381-385. doi: 10.1007/ s00268-016-3692-x. Erratum in: World J Surg. 2017 Feb;41(2):380.

8 Debacker M, Hubloue I, Dhondt E, et al. Utstein-style template for uniform data reporting of acute medical response in disasters. PLoS Curr. 2012;4:e4f6cf3e8df15a.

9 Kar-Purkayastha I, Clarke M, Murray V. Dealing with disaster databases What can we learn from health and systematic reviews? Application in practice. PLoS Curr. 2011:3. RRN1272.

10 Jafar A, Norton I, Lecky F, et al. A literature review of medical record keeping by foreign medical teams in sudden onset disasters. Prehosp Disaster Med. 2015;30:216-222.

11 Noji EK. The public health consequences of disasters. Prehosp Disaster Med. 2000;15:147-157.

12 Chang MP, Simkin DJ, de Lara ML, et al. Characterizing hospital admissions to a tertiary care hospital after Typhoon Haiyan. Disaster Med Public Health Prep. 2016 Apr10(2):240-247. doi: 10.1017/dmp.2015.165. Epub 2016 Feb 1.

13 Gerdin M, Wladis A, von Schreeb J. Foreign field hospitals after the 2010 Haiti earthquake: how good were we? Emerg Med J. 2013; 30:e8.

14 British Broadcasting Corporation World News Rajesh Mirchandani. Philippines Typhoon: Inside Tacloban field hospital set up by German and Belgian medics in Palo [Video]. https://www.youtube.com/watch? $\mathrm{v}=\mathrm{hTbDsEx}$ 3fFo. Accessed May 10, 2017.

15 United Nations International Children's Emergency Fund. A summary of the United Nations Convention on the Rights of the Child. UNICEF. http://www.ohchr.org/EN/ProfessionalInterest/Pages/CRC.aspx. Accessed May 10, 2017.

16 Bambrick AT, Passman DB, Torman RM, et al. Optimizing the use of chief complaint \& diagnosis for operational decision making: An EMR case study of the 2010 Haiti earthquake. PLoS Curr. 2014:6. pii: ecurrents.dis.2c6c4d44ddc0260af0867e0bc30b85aa7.

17 Mowafi $\mathrm{H}$, Dworkis D, Bisanzo M, et al. Making recording and analysis of chief complaint a priority for global emergency care research in lowincome countries. Acad Emerg Med. 2013;20:1241-1245.

18 Connolly MA. ed. Communicable Disease Control in Emergencies: A Field Manual. Geneva: World Health Organization; 2005:204-231.

19 The Sphere Project. Sphere Handbook 2011 (English). http://www. sphereproject.org/handbook/. Accessed May 10, 2017.

20 van Berlaer G, Staes T, Danschutter D, et al, Disaster preparedness and response improvement: comparison of the 2010 Haiti earthquake-related diagnoses with baseline medical data. Eur J Emerg Med. Published Online First: 22 Mar 2016. doi: 10.1097/MEJ.0000000000000387.

21 Roggen I, van Berlaer G, Gijs G, et al. Clinical characteristics of the inhabitants of an internally displaced persons camp in Brazzaville, Republic of Congo after the arms dump blast on march 4, 2012. Prehosp Disaster Med. 2014;29:516-520.

22 van Berlaer G, Bohle Carbonell F, Manantsoa S, et al. A refugee camp in the centre of Europe: clinical characteristics of asylum seekers arriving in Brussels. BMJ Open. 2016 Nov 24;6(11):e013963. doi: 10.1136/bmjopen2016-013963.

23 World Health Organization. International Statistical Classification of Diseases and Health Related Problems: 10th revision. Geneva: World Health Organization; 2010; http://www.who.int/classifications/icd/en/. Accessed May 10, 2017. 
24 World Medical Association. WMA declaration of Helsinki - ethical principles for medical research involving human subjects. Bull World Health Organ. 2001;79:373-374.

25 Institute for Health Metrics and Evaluation at the University of Washington. GBD Profile: Philippines: Global Burden of Diseases, Injuries, and Risk Factors Study 2010. http://www.healthdata.org/sites/ default/files/files/country_profiles/GBD/ihme_gbd_country_report_philip pines.pdf. Accessed May 10, 2017.

26 Salazar MA, Pesigan A, Law R, et al. Post-disaster health impact of natural hazards in the Philippines in 2013. Glob Health Action. 2016 May 17;9:31320. doi: 10.3402/gha.v9.31320. eCollection 2016.

27 Gamulin A, Armenter-Duran J, Assal M, et al. Conditions found among pediatric survivors during the early response to natural disaster: a prospective case study. J Pediatr Orthop. 2012 Jun32(4):327-333. doi: 10.1097/BPO.0b013e31825197ec.

28 Kim YW, Kim SY, Kim H, et al. Disaster-related injury management: high prevalence of wound infection after super typhoon Haiyan. Disaster Med Public Health Prep. 2016 Feb10(1):28-33. doi: 10.1017/dmp.2015.100. Epub 2015 Sep 2.

29 Connolly M, Gayer M, Ryan M, et al. Communicable diseases in complex emergencies: impact and challenges. Lancet. 2004;364:1974-1983.

30 Saito-Obata M, Saito M, Tan TC, et al. Laboratory diagnosis for outbreak-prone infectious diseases after Typhoon Yolanda (Haiyan), Philippines. PLoS Curr. 2016 Oct 21:8. pii: ecurrents.dis.9c3cb7b01ec 2d04eef2406dbe03d253d.

31 Robinson B, Alatas MF, Robertson A, et al. Natural disasters and the lung. Respirology. 2011 Apr16(3):386-395. doi: 10.1111/j.1440-1843.2011.01923.x.

32 Bellos A, Mulholland K, O'Brien K, et al. The burden of acute respiratory infections in crisis-affected populations: a systematic review. Confl Health. 2010;4:3.

33 Watson JT, Gayer M, Connolly MA. Epidemics after natural disasters. Emerg Infect Dis. 2007;13(1):1-5.

34 Lew W, Vianzon R, Garfin AM, et al. Restarting the tuberculosis programme post-Haiyan. Western Pac Surveill Response J. 2015 Nov 6;6 (Suppl 1):91-95. doi: 10.5365/WPSAR.2015.6.2.HYN_009. eCollection 2015 Oct-Dec.

35 Ventura RJ, Muhi E, de los Reyes VC, et al. A community-based gastroenteritis outbreak after Typhoon Haiyan, Leyte, Philippines, 2013. Western Pac Surveill Response J. 2015 Jan 10;6(1):1-6. doi: 10.2471/ WPSAR.2014.5.1.010. eCollection 2015 Jan-Mar.

36 Savage E, Christian MD, Smith S, et al. The Canadian Armed Forces medical response to Typhoon Haiyan. Can J Surg. 2015 Jun; 58(3 suppl 3):S146-S152.

37 Dolhun E. Aftermath of Typhoon Haiyan: the imminent epidemic of waterborne illnesses in Leyte, Philippines. Disaster Med Public Health Prep. 2013 Dec; 7(6):547-548. doi: 10.1017/dmp.2013.114.

38 Saito M, Miyahara S, Villanueva SY, et al. PCR and culture identification of pathogenic Leptospira spp. from coastal soil in Leyte, Philippines, after a storm surge during Super Typhoon Haiyan (Yolanda).
Appl Environ Microbiol. 2014 Nov; 80(22):6926-6932. doi: 10.1128/ AEM.02568-14. Epub 2014 Aug 29.

39 Aumentado C, Cerro BR, Olobia L, et al. The prevention and control of dengue after Typhoon Haiyan. Western Pac Surveill Response J. 2015 Nov 6;6 (Suppl 1):60-65. doi: 10.5365/WPSAR.2015.6.3.HYN_018. eCollection 2015 Oct-Dec.

40 Burke RV, Iverson E, Goodhue CJ, et al. Disaster and mass casualty events in the pediatric population. Semin Pediatr Surg. 2010;19 (4):265-270. doi: 10.1053/j.sempedsurg.2010.06.003.

42 Martinez RE, Quintana R, Go JJ, et al. Surveillance for and issues relating to noncommunicable diseases post-Haiyan in Region 8. Western Pac Surveill Response J. 2015 Nov 6;6(Suppl 1):21-24. doi: 10.5365/ WPSAR.2015.6.3.HYN_020. eCollection 2015 Oct-Dec.

43 Albukrek D, Mendlovic J, Marom T. Typhoon Haiyan disaster in the Philippines: paediatric field hospital perspectives. Emerg Med J. 2014 Dec; 31(12):951-953. doi: 10.1136/emermed-2014-203777. Epub 2014 Sep 22.

41 North CS, Pfefferbaum B. Mental health response to community disasters: a systematic review. JAMA. 2013;310:507-518.

44 World Health Organization. Chapter 6, Western Pacific Region. Global Burden of Disease. http://www.wpro.who.int/health_research/documents/ dhs_hr_health_in_asia_and_the_pacific_11_chapter_6_burden_of_disease. pdf?ua =1. Accessed May 10, 2017.

$45 \mathrm{Kim} \mathrm{H}$, Han SB, Kim JH, et al. Post-Nargis medical care: experience of a Korean Disaster Relief Team in Myanmar after the cyclone. Eur J Emerg Med. 2010 Feb17(1):37-41. doi: 10.1097/MEJ.0b013e32832d3bc6.

46 Ramesh A, Blanchet K, Ensink JH, et al. Evidence on the effectiveness of water, sanitation, and hygiene (wash) interventions on health outcomes in humanitarian crises: a systematic review. PLoS One. 2015 Sep 23;10 (9):e0124688. doi: 10.1371/journal.pone.0124688. eCollection 2015.

47 United Nations Office for Disaster Risk Reduction. Sendai Framework for Disaster Risk Reduction. http://www.unisdr.org/we/coordinate/sendaiframework. Accessed November 29, 2017.

48 Norton I, von Schreeb J, Aitken P, et al. Classification and minimum standards for foreign medical teams in sudden onset disasters. Geneva: World Health Organisation; 2013; http://www.who.int/hac/global_health_ cluster/fmt_guidelines_september2013.pdf. Accessed May 10, 2017.

49 World Health Organization. Manual for the Health Care of Children in Humanitarian Emergencies. Geneva: World Health Organization; 2008; http://apps.who.int/iris/bitstream/10665/43926/1/9789241596879_eng. pdf. Accessed May 10, 2017.

50 Benigno MR, Kleinitz P, Calina L, et al. Responding to the health and rehabilitation needs of people with disabilities post-Haiyan. Western Pac Surveill Response J. 2015 Nov 6;6 (Suppl 1):53-59. doi: 10.5365/ WPSAR.2015.6.2.HYN_010. eCollection 2015 Oct-Dec.

51 Evidence Aid Priority Setting Group. Prioritization of themes and research questions for health outcomes in natural disasters, humanitarian crises or other major health care emergencies. PLoS Curr. 2013:5. pii: ecurrents.dis.c9c4f4db9887633409182d2864b20c31. 